\title{
Carbonate system and acidification of the Adriatic Sea
}

\author{
B. KRAJNC ${ }^{1 *}$, J. FAGANELI ${ }^{2}$ AND N. OGRINC
}

${ }^{1}$ Jožef Stefan Institute, Jamova cesta 39, 1000 Ljubljana,

Slovenia, EU (*correspondence: bor.krajnc@ijs.si; nives.ogrinc@ijs.si)

${ }^{2}$ National Institute of Biology, Marine Biological Station, Fornače 41, 6330 Piran, Slovenia, EU

(jadran.faganeli@nib.si)

The carbonate system of the coastal waters plays an important role in the global carbon budget. These waters act as a medium of exchange for oceanic, atmospheric, riverine, sediment, biota and terrestrial carbon pools. Recent research indicates that increasing $\mathrm{CO}_{2}$ absorption in estuarine waters can result in an additional $\mathrm{pH}$ decline due to the eutrophication-induced acidification. The Adriatic Sea is currently a $\mathrm{CO}_{2}$ sink with an annual flux of approximately -1.2 to -3 molC $\mathrm{m}^{-2} \mathrm{yr}^{-1}$ which is comparable ( -4 to -5 molC $\mathrm{m}^{-2} \mathrm{yr}^{-1}$ ) to a net sink in NW Mediterranean.

The study presented in this study was conducted in the Gulf of Trieste, which is a small and shallow marine basin in the northern part of the Adriatic Sea. Total alkalinity (TA) in the Adriatic (2.6-2.7 mM) is in the upper range of TA measured in the Mediterranean Sea primarily because riverine inputs transport carbonates dissolved from Alpine dolomites and karstic watersheds. Saturation indices indicate that the waters are supersaturated with respect to calcite $\left(\Omega_{\mathrm{Ca}}\right)$ and aragonite $\left(\Omega_{\mathrm{Ar}}\right)$ throughout the year. Indices are considerably lower in the bottom water layer which is related to benthic remineralization processes. The seasonal changes of the chemical and environmental conditions and relatively small size of the area influence the microbial community composition, function (growth, enzymatic activity) and nutrient biogeochemical cycles. Significant effects on calcifying organisms and phytoplankton are expected, while the effects of possible ocean acidification on microbiallydriven processes are not definite yet.

Understanding the processes that control the transport and fate of greenhouse gasses such as $\mathrm{CO}_{2}$ and its changes through the time are important aspects of protecting the ocean environment. The presented research takes also part of a STELLAR project where new stable isotope reference materials for atmospheric $\mathrm{CO}_{2}$ measurements will be developed that will greatly contribute to the estimation of processes that influence the carbon dynamics in the marine environment. 